\title{
Kinetics and Mechanism of Formation of 1:1 Complex Between Chromium(III) with 1,3-Propane Diaminetetraacetate in Aqueous Acidic Media
}

\author{
M. F. ABDEL-MESSIH
}

Chemistry Department, Faculty of Science, Ain Shams University, Abbassia, Cairo, Egypt michel_lhay86@yahoo.com

Received 14 August 2012 / Accepted 19 September 2012

\begin{abstract}
The kinetics of the formation of 1:1 complex of chromium(III) with 1,3-propanediamine $N, N, N^{\prime} N^{\prime}$-tetraacetate (1,3-pdta) was followed spectrophotometrically at $\lambda_{\max }=552 \mathrm{~nm}$. The reaction was found to be first order in chromium(III). Increasing the 1,3-pdtp concentration from $2.2 \times 10^{-2}$ to $8.8 \mathrm{~mol} \mathrm{dm}^{-3}$ accelerated the reaction rate. Increasing the $\mathrm{pH}$ from 3.3 to 4.7 accelerated the reaction rate, the reaction rate was also retarded by increasing ionic strength and dielectric constant of the reaction medium. A mechanism was suggested to account for the results obtained which involves ion pair formation between the various species of the reactants. Value of $37.1 \pm 3 \mathrm{~kJ} \mathrm{~mol}^{-1}$ was obtained for the energy of activation and $-195.6 \pm 6 \mathrm{JK}^{-1} \mathrm{~mol}^{-1}$ for the entropy of activation indicate an associative mechanism for the reaction. The logarithms of the formation constant of 1:1 complex formed for complex formed was found 7.31.
\end{abstract}

Keywords: Kinetic, Mechanism, Substitution, 1,3-Propanediaminetetraacetic acid, Chromium(III)

\section{Introduction}

In ligand substitution reactions which represent a major type of inorganic processes, one or more ligands around a metal ion are replaced by other ligands ${ }^{1}$. Chromium(III) is classically known as a substitution-inert metal ion ${ }^{2}$.

Aminocarboxylate chelating agents complex strongly with most metals, thus altering metal bioavailability and mobility in the environment ${ }^{3}$. These compounds are widely used in industrial, medical and agricultural purposes ${ }^{4-12}$, These compounds are used as laundry detergent builders, boiler scale inhibitors, in metal plating and cleaning operations, in textile manufacture and in paper and cellulose production. 1,3-Propanediamine $N, N, N^{\prime} N^{\prime}$-tetraacetate (1,3-pdta) a member of the aminocarboxylate family.

Although the experimental system and reaction studied here is very simple in nature, elucidation of the mechanism in this model system has implications for a variety of more complex homogeneous and heterogeneous phenomena involving metal-organic complexes (e.g., metal ion transport, bioavailability and toxicity).

This study deals with the kinetic of complexation of chromium(III) with 1,3-pdta in weak acid solution. The study involves factors affecting the rate of reaction. The formation constant of the studied complex is also measured. 


\section{Experimental}

All chemicals were of pure grade and were used without further purification. The 1,3 -propanediaminetetraacetic acid $\left(\mathrm{H}_{4} 1,3\right.$ - pdta) was prepared using a previously described procedure $^{13}$. Stock solution of $\left(0.1 \mathrm{~mol} \mathrm{dm}^{-3}\right)$ of hexaaquachromium(III) was prepared by dissolving $\mathrm{CrCl}_{3}$ in double distilled water and leaving the solution for 48 hours at $45^{\circ} \mathrm{C}$, where upon green colour of $\mathrm{CrCl}_{3}$ changed to blue color of aquachromium(III) ${ }^{14}$. All solutions were prepared using double distilled water. The absorbance measurements were performed using thermostatted 292 Cecil spectrophotometer and $\mathrm{pH}$ measurements were conducted with Griffin pH meter fitted with glass-calomel electrode standardized by potassium hydrogen phthalate.

Kinetic experiments were conducted by mixing thermostatted solutions of chromium(III) and the 1,3- pdta and adjusting hydrogen ion concentration to the required value with potassium hydroxide or perchloric acid. Ionic strength was adjusted by sodium perchlorate solution. The solution was then introduced into the reaction vessel, which was previously thermostatted to the desired temperature and the reaction was followed spectrophotometrically at $\lambda_{\max }=552 \mathrm{~nm}$ for the complex formed. The reaction rate was followed under pseudo first order conditions where at least ten fold excess of the ligand concentration over the reactant chromium(III) concentration was always ensured. Values of the observed first order rate constant, $k_{\text {obs }}$, were determined graphically for each run by plotting $\log \left(A_{\infty}-A_{t}\right)$ versus time, $t$, where $A$ denotes the measured absorbance and the subscripts refer to time of reaction. The absorbance $\left(\mathrm{A}_{\infty}\right)$ was obtained directly after ensuring completion of the reaction. First order plots were linear for more than $85 \%$ of the reaction progress.

\section{Results and Discussion}

The reaction was found to be first order in chromium(III), the observed first order rate constants, $\mathrm{k}_{\mathrm{obs}}$, did not vary with chromium(III) concentration, (Table 1) ensuring first order kinetics in chromium(III).

The effect of varying 1,3-pdta concentration, at different $\mathrm{pH}$ values on the rate of reaction was also studied, (Table 1 ) and a plot of the first order rate constant, $\mathrm{k}_{\mathrm{obs}}$, against 1,3- pdta concentration was nonlinear, (Figure 1), indicating formation of ion pair ${ }^{15,16}$.

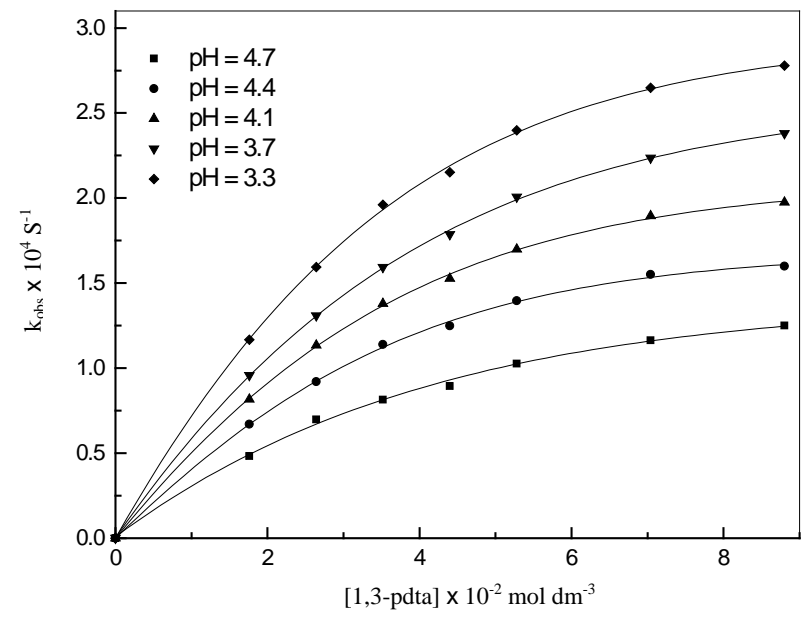

Figure 1. Variation of $\mathrm{k}_{\mathrm{obs}}$ with [1,3- pdta] at various $\mathrm{pH} ; I=0.6 \mathrm{~mol} \mathrm{dm}{ }^{-3}, t=35{ }^{0} \mathrm{C}$, $[\mathrm{Cr}(\mathrm{III})]=8.8 \times 10^{-3} \mathrm{~mol} \mathrm{dm}^{-3}$ 
Increasing the ionic strength, I, of the reaction medium from 0.7 to $1.25 \mathrm{~mol} \mathrm{dm}^{-3}$ (adjusted by sodium perchlorate) the reaction rate (Table 1). Applying Bronsted Bjerrum equation $^{17,18}$, a linear relationship was obtained by plotting $\log \mathrm{k}_{\mathrm{obs}}$ versus $\sqrt{ } \mathrm{I}$, (Figure 2) indicating that reaction involves ion pairing formation

The effect of the dielectric constant on the rate of reaction was studied using different ratios of ethanol-water mixtures. The values of the observed first order rate constant, $\mathrm{k}_{\mathrm{obs}}$ increased with decreasing the dielectric constant of the reaction medium, $\varepsilon$, (Table 1). Applying Bjerrum's equation ${ }^{17}$, a plot of $\log \mathrm{k}_{\mathrm{obs}}$ versus $1 / \varepsilon$ was linear with positive slopes, (Figure 3) indicating that the reaction is an ion pair type ${ }^{19}$.

Table 1. Values of $k_{o b s}$ under various conditions

\begin{tabular}{|c|c|c|c|c|c|c|c|c|c|}
\hline \multirow{2}{*}{$\begin{array}{l}{[\mathrm{Cr}(\mathrm{III})] \times 10^{3}} \\
\mathrm{~mol} \mathrm{dm}^{-3}\end{array}$} & \multirow{2}{*}{$\begin{array}{c}{[1,3 \text { pdta }]} \\
\quad x 10^{2} \\
\mathrm{~mol} \mathrm{dm}^{-3}\end{array}$} & \multirow{2}{*}{$\begin{array}{c}t \\
{ }^{\circ} \mathrm{C}\end{array}$} & \multirow{2}{*}{$\begin{array}{r}I \text { mol } \\
\mathrm{dm}^{-3}\end{array}$} & \multirow[t]{2}{*}{$\varepsilon$} & \multicolumn{5}{|c|}{$k_{o b s} \times 10^{4}, \mathrm{~s}^{-1}$} \\
\hline & & & & & $\mathrm{pH}=3.3$ & 3.7 & 4.1 & 4.4 & 4.7 \\
\hline 4.4 & \multirow{7}{*}{8.80} & \multirow{7}{*}{35} & \multirow{7}{*}{0.6} & & & & 41.959 & & \multirow{30}{*}{$\begin{array}{l}1.168 \\
1.595 \\
1.960 \\
2.151 \\
2.399 \\
2.648 \\
2.779\end{array}$} \\
\hline 6.0 & & & & & & & 1.963 & & \\
\hline 7.2 & & & & & & & 1.971 & & \\
\hline 8.8 & & & & & & & 1.969 & & \\
\hline 10.4 & & & & & & & 1.977 & & \\
\hline 12.0 & & & & & & & 1.983 & & \\
\hline \multirow[t]{11}{*}{13.6} & & & & & & & 1.975 & & \\
\hline & 1.76 & & & & 0.482 & 0.670 & 0.817 & 0.957 & \\
\hline & 2.64 & & & & 0.699 & 0.920 & 1.135 & 1.308 & \\
\hline & 3.52 & & & & 0.815 & 1.139 & 1.380 & 1.593 & \\
\hline & 4.40 & 35 & 0.6 & & 0.894 & 1.249 & 1.527 & 1.786 & \\
\hline & 5.28 & & & & 1.026 & 1.396 & 1.698 & 2.007 & \\
\hline & 7.04 & & & & 1.163 & 1.551 & 1.895 & 2.236 & \\
\hline & 8.80 & & & & 1.250 & 1.599 & 1.975 & 2.379 & \\
\hline & & & 0.6 & & & & 1.975 & & \\
\hline & & & 0.7 & & & & 1.785 & & \\
\hline & & & 0.8 & & & & 1.550 & & \\
\hline \multirow[t]{8}{*}{8.8} & 8.80 & 35 & 0.9 & & & & 1.346 & & \\
\hline & & & 1.0 & & & & 1.251 & & \\
\hline & & & 1.1 & & & & 1.131 & & \\
\hline & & & 1.2 & & & & 1.045 & & \\
\hline & & & & 78.00 & & & 1.234 & & \\
\hline & & & & 75.32 & & & 1.287 & & \\
\hline & & & & 72.63 & & & 1.353 & & \\
\hline & & & & 69.95 & & & 1.433 & & \\
\hline \multirow[t]{5}{*}{8.8} & 8.80 & 25 & 0.6 & 67.26 & & & 1.503 & & \\
\hline & & & & 64.58 & & & 1.591 & & \\
\hline & & & & 61.89 & & & 1.693 & & \\
\hline & & & & 59.21 & & & 1.819 & & \\
\hline & & & & 56.52 & & & 1957 & & \\
\hline
\end{tabular}




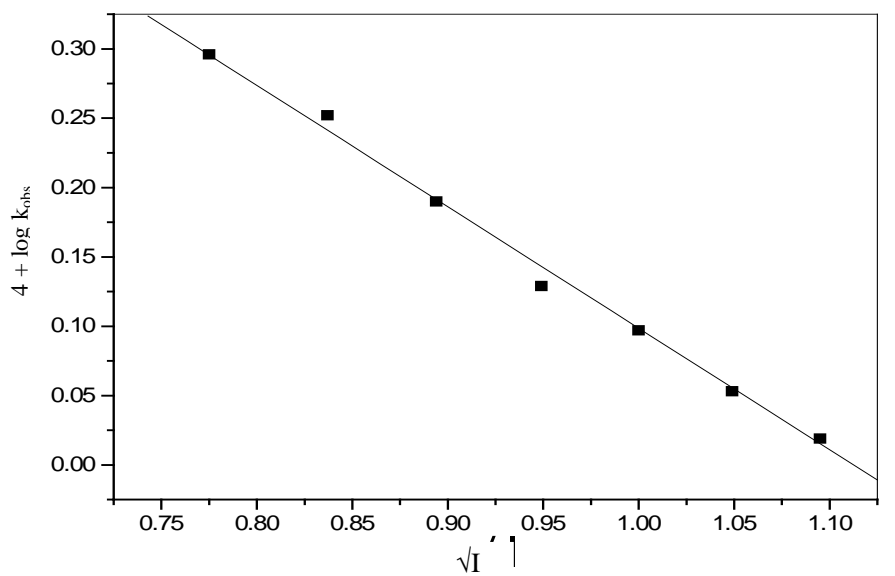

Figure 2. Variation of $\log \mathrm{k}_{\mathrm{obs}}$ with $\sqrt{\mathrm{I}}$; [1,3- pdta] $=8.8 \times 10^{-2} \mathrm{~mol} \mathrm{dm}^{-3}, \mathrm{pH}=4.1$, $[\mathrm{Cr}(\mathrm{III})]=8.8 \times 10^{-3} \mathrm{~mol} \mathrm{dm}^{-3}, t=35^{\circ} \mathrm{C}$

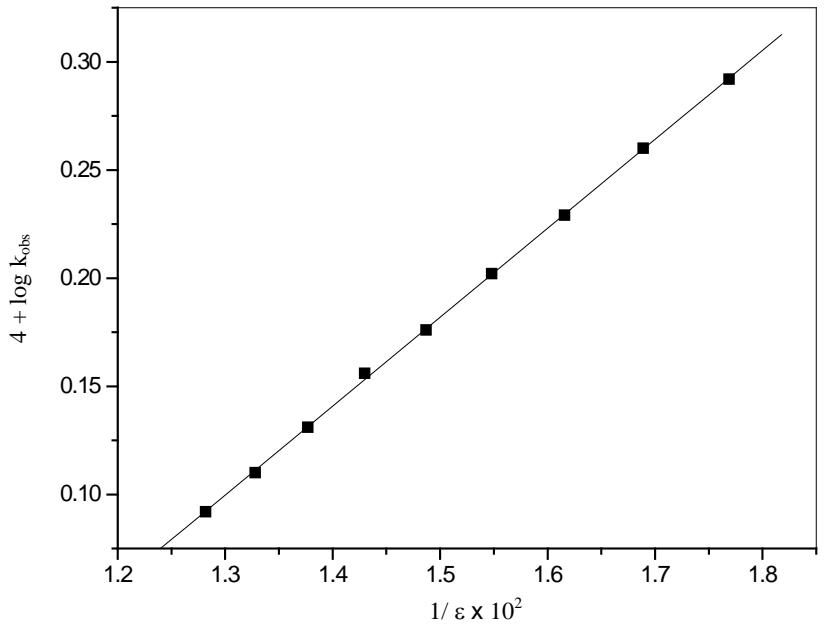

Figure 3. Variation of $\log \mathrm{k}_{\mathrm{obs}}$ with $1 / \varepsilon$ in ethanol-water mixture; $t=25{ }^{0} \mathrm{C}, \mathrm{pH}=4.1$, $[\mathrm{Cr}(\mathrm{III})]=8.8 \times 10^{-3} \mathrm{~mol} \mathrm{dm}^{-3}, \mathrm{I}=0.7 \mathrm{~mol} \mathrm{dm}^{-3},[1,3-\mathrm{pdta}]=8.8 \times 10^{-2} \mathrm{~mol} \mathrm{dm}^{-3}$

The effect of $\mathrm{pH}$ on the rate of reaction was studied in the range from 3.0 to 4.7 at various temperatures, (Table 2). The results obtained show that the reaction is accelerated by lowering hydrogen ion concentration.

Table 2. Kinetic data for the interaction of $\mathrm{Cr}(\mathrm{III})$ with 1,3-pdta at various temperature and proton concentration; $[\mathrm{Cr}(\mathrm{III})]=8.8 \times 10^{-3} \mathrm{~mol} \cdot \mathrm{dm}^{-3}$, [1,3- pdta $]=11 \times 10^{-2} \mathrm{~mol} \cdot \mathrm{dm}^{-3}, \mathrm{I}=0.6 \mathrm{~mol} \cdot \mathrm{dm}^{-3}$

\begin{tabular}{cccccc}
\hline \multirow{2}{*}{$\mathrm{pH}$} & \multicolumn{5}{c}{$\mathrm{k}_{\text {obs }} \times 10^{4} / \mathrm{s}^{-1}$} \\
\cline { 2 - 6 } & $25^{\circ} \mathrm{C}$ & $30^{\circ} \mathrm{C}$ & $35^{\circ} \mathrm{C}$ & $40^{\circ} \mathrm{C}$ & $45^{\circ} \mathrm{C}$ \\
\hline 3.3 & 0.766 & 1.012 & 1.250 & 1.531 & 2.007 \\
3.7 & 1.007 & 1.257 & 1.539 & 2.019 & 2.530 \\
4.1 & 1.234 & 1.567 & 1.975 & 2.475 & 3.125 \\
4.4 & 1.475 & 1.853 & 2.379 & 3.009 & 3.764 \\
4.7 & 1.703 & 2.164 & 2.785 & 3.508 & 4.355 \\
\hline
\end{tabular}


The dependence of $k_{o b s}$ on hydrogen ion concentration can be explained by in following equilibriums between the various species of each reactant which are present in the reaction medium $^{20,21}$. The pentaaquahydroxochromium(III) species is more reactive than the hexaaquachromium(III) due to the presence of $\mathrm{OH}^{-}$which causes an increase of water liabilities due to its $\pi$-bonding ability ${ }^{22-30}$.

The results obtained can be explained by the following mechanism for the interaction between the predominant species of chromium(III) with the predominant species of 1,3- pdta in the $\mathrm{pH}$ range under investigation.

$$
\begin{aligned}
& {\left[\mathrm{Cr}\left(\mathrm{H}_{2} \mathrm{O}\right)_{6}\right]^{+3} \stackrel{\mathrm{K}_{\mathrm{h}}}{=}\left[\mathrm{Cr}\left(\mathrm{H}_{2} \mathrm{O}\right)_{5} \mathrm{OH}\right]^{+2}+\mathrm{H}^{+} \quad \mathrm{pK}_{\mathrm{h}}=4.1} \\
& \mathrm{H}_{4} \mathrm{~L} \underset{+\mathrm{H}^{+}}{\stackrel{\mathrm{K}_{1}}{\rightleftharpoons}} \mathrm{H}_{3} \mathrm{~L}^{-} \frac{\mathrm{K}_{2}}{+\mathrm{H}^{+}} \mathrm{H}_{2} \mathrm{~L}^{-2} \quad \mathrm{pK}_{1}=1.88 \quad \mathrm{pK}_{2}=2.47 \\
& {\left[\mathrm{Cr}\left(\mathrm{H}_{2} \mathrm{O}\right)_{6}\right]^{+3}+\mathrm{H}_{3} \mathrm{~L}^{-} \stackrel{\mathrm{K}_{\mathrm{IP} 1}}{\rightleftharpoons} \mathrm{IP}_{1}} \\
& {\left[\mathrm{Cr}\left(\mathrm{H}_{2} \mathrm{O}\right)_{5} \mathrm{OH}\right]^{+2}+\mathrm{H}_{3} \mathrm{~L}^{-} \stackrel{\mathrm{K}_{\mathrm{IP} 2}}{\rightleftharpoons} \mathrm{IP}_{2}} \\
& {\left[\mathrm{Cr}\left(\mathrm{H}_{2} \mathrm{O}\right)_{6}\right]^{+3}+\mathrm{H}_{2} \mathrm{~L}^{-2} \stackrel{\mathrm{K}_{\mathrm{IP} 3}}{\rightleftharpoons} \mathrm{IP}_{3}} \\
& {\left[\mathrm{Cr}\left(\mathrm{H}_{2} \mathrm{O}\right)_{5} \mathrm{OH}\right]^{+2}+\mathrm{H}_{2} \mathrm{~L}^{-2} \stackrel{\mathrm{K}_{\mathrm{IP} 4}}{=} \mathrm{IP}_{4}} \\
& \mathrm{IP}_{1} \underset{\text { slow }}{\stackrel{\mathrm{k}_{1}}{\longrightarrow}}\left[\mathrm{Cr}\left(\mathrm{H}_{2} \mathrm{O}\right)_{5}\left(\mathrm{H}_{3} \mathrm{~L}\right)\right]^{+2} \stackrel{\text { fast }}{\longrightarrow} \text { product } \\
& \mathrm{IP}_{2} \underset{\text { slow }}{\stackrel{\mathrm{k}_{2}}{\longrightarrow}}\left[\mathrm{Cr}\left(\mathrm{H}_{2} \mathrm{O}\right)_{5}(\mathrm{OH})\left(\mathrm{H}_{3} \mathrm{~L}\right)\right]^{+} \stackrel{\text { fast }}{\longrightarrow} \text { product } \\
& \mathrm{IP}_{3} \underset{\text { slow }}{\stackrel{\mathrm{k}_{3}}{\longrightarrow}}\left[\mathrm{Cr}\left(\mathrm{H}_{2} \mathrm{O}\right)_{5}\left(\mathrm{H}_{2} \mathrm{~L}\right)\right]^{+} \stackrel{\text { fast }}{\longrightarrow} \text { product } \\
& \mathrm{IP}_{4} \underset{\text { slow }}{\stackrel{\mathrm{k}_{4}}{\longrightarrow}}\left[\mathrm{Cr}\left(\mathrm{H}_{2} \mathrm{O}\right)_{5}(\mathrm{OH})\left(\mathrm{H}_{2} \mathrm{~L}\right)\right] \stackrel{\text { fast }}{\longrightarrow} \text { product }
\end{aligned}
$$

$\mathrm{IP}_{1}-\mathrm{IP}_{4}$ are the hexaaquo and pentaaquohydroxy ion pair complexes of chromium(III) and 1,3- pdta.

The rate of exchange of the first ligand molecule, in the inner coordination sphere of the metal center is slow and therefore the rate determining equations (7-10 $)^{24,25,30}$. As soon as one carboxyl group of the ligand enters into the inner sphere, the electron density on the chromium center increases owing to the inductive effect and as results the remaining ligands are labilized easily and its substitution is rapid. From the previous mechanism, the first order rate constant is derived as;

$$
k_{\text {obs }}=\frac{\left(k_{1} K_{I P 1}\left[H^{+}\right]+k_{2} K_{I P 2} K_{2}+k_{3} K_{I P 3} K_{h}+k_{4} K_{I P 4} \frac{K_{2} K_{h}}{\left[H^{+}\right]}\right)[1,3-\text { pdta }]}{\left(\frac{\left[H^{+}\right]^{2}}{K_{1}}+\left[H^{+}\right]+K_{2}\right)\left(1+\frac{K_{h}}{\left[H^{+}\right]}\right)+\left(\left(K_{I P 1}\left[H^{+}\right]+K_{I P 2} K_{2}+K_{I P 3} K_{h}+K_{I P 4} \frac{K_{2} K h}{\left[H^{+}\right]}\right)[1,3-\text { pdta }]\right)}
$$

by inversing equation (11) we get equation

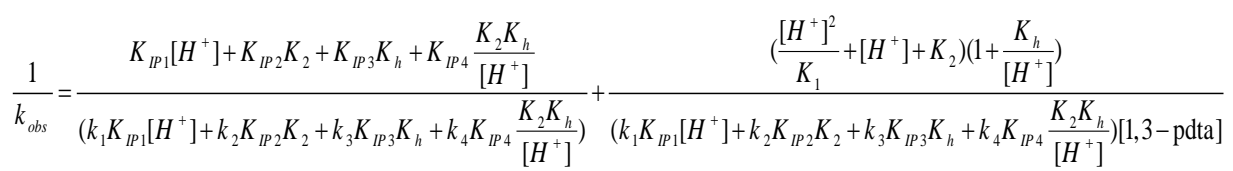


and a plot of $1 / k_{o b s}$ versus $1 /[1,3-$ pdta] gave straight line with slopes

$$
S=\frac{\left(\frac{\left[H^{+}\right]^{2}}{K_{1}}+\left[H^{+}\right]+K_{2}\right)\left(1+\frac{K_{h}}{\left[H^{+}\right]}\right)}{\left(k_{1} K_{I P 1}\left[H^{+}\right]+k_{2} K_{I P 2} K_{2}+k_{3} K_{I P 3} K_{h}+k_{4} K_{I P 4} \frac{K_{2} K_{h}}{\left[H^{+}\right]}\right)}
$$

and intercepts, I

$$
\begin{gathered}
I=\frac{K_{I P 1}\left[H^{+}\right]+K_{I P 2} K_{2}+K_{I P 3} K_{h}+K_{I P 4} \frac{K_{2} K_{h}}{\left[H^{+}\right]}}{\left(k_{1} K_{I P 1}\left[H^{+}\right]+k_{2} K_{I P 2} K_{2}+k_{3} K_{I P 3} K_{h}+k_{4} K_{I P 4} \frac{K_{2} K_{h}}{\left[H^{+}\right]}\right)} \\
\text {and } \frac{I}{S}=\frac{K_{I P 1}\left[H^{+}\right]+K_{I P 2} K_{2}+K_{I P 3} K_{h}+K_{I P 4} \frac{K_{2} K_{h}}{\left[H^{+}\right]}}{\left(\frac{\left[H^{+}\right]^{2}}{K_{1}}+\left[H^{+}\right]+K_{2}\right)\left(1+\frac{K_{h}}{\left[H^{+}\right]}\right)}
\end{gathered}
$$

The values of the ion pair formation constants, $K_{I P}$ and the rate constants of the rate determining steps, $k$, were calculating by plotting $1 / k_{\text {obs }}$ versus $1 /$ [ [1,3- pdta] at $\mathrm{pH}$, (Figure 4). Values 7.11, 14.78, 10.15 and $16.81 \mathrm{~mol}^{-1} \mathrm{dm}^{3}$ for the ion pair formation constants, $K_{I P}$ and 1.83, 4.81, 2.97 and $5.23 \times 10^{-3} \mathrm{~s}^{-1}$ for the rate determining steps, $k$, respectively were calculating by applying equation (13-15) at different hydrogen ion concentrations and taking the values of $K_{1}, K_{2}$ and $K_{h}$ from equations $(1,2)$.

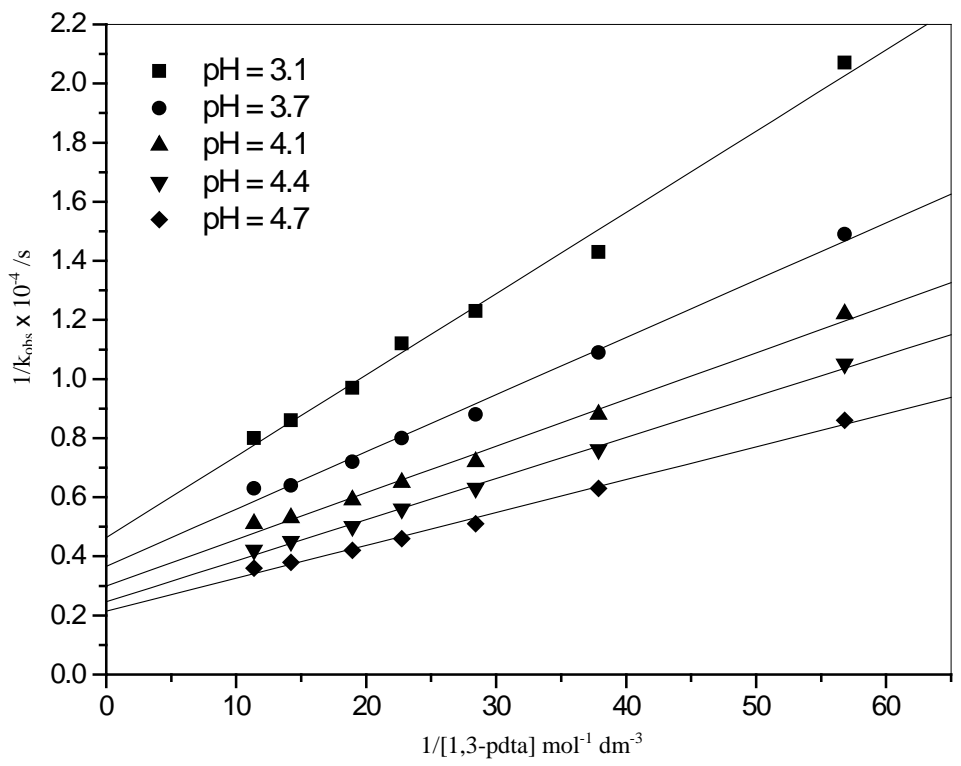

Figure 4. Variation of $1 / k_{o b s}$ with $1 /$ [1,3- pdta]; $[\mathrm{Cr}(\mathrm{III})]=8.8 \times 10^{-3} \mathrm{~mol} \mathrm{dm}{ }^{-3}, t=35{ }^{0} \mathrm{C}$, $I=0.6 \mathrm{~mol} \mathrm{dm}^{-3}, \mathrm{pH}=4.1$

The effect of temperature on the rate reaction was also studied at different hydrogen ion concentrations (Table 2). The activation parameters were calculating using Arrhenius plots values and the Eyring equation and were found to be $37.1 \pm 3 \mathrm{~kJ} \mathrm{~mol}^{-1}$ for the energy of activation and $-195.6 \pm 6 \mathrm{~J} \mathrm{~K}^{-1} \mathrm{~mol}^{-1}$ for the entropy of activation. 
It is well known that substitution reactions of hexaaquachromium(III) with a variety of ligands proceed by associative ${ }^{19,31,32}$ and dissociative ${ }^{33,34}$ mechanisms. Swaddle ${ }^{35,36}$ and Lincoln $^{37}$ have reviewed that the activation parameters and mechanism of octahedral substitution and concluded that an associative mechanism is operative for octahedral cationic complexes of trivalent metal ions except for Co(III) with ionic radii greater than $60 \mathrm{pm}$, which demand associative character for substitution reaction of $\left[\mathrm{Cr}\left(\mathrm{H}_{2} \mathrm{O}\right)_{6}\right]^{+3}$.

The associative mechanism is further supported by i-lowering of enthalpy and large negative entropy for substitution of water by ligand compare to water exchange (for water ${ }^{38}$ exchange $\Delta H^{*}=109.6 \mathrm{~kJ} \mathrm{~mol}^{-1}$ and $\left.\Delta S^{*}=+12 \mathrm{JK}^{-1} \mathrm{~mol}^{-1}\right)$ ii-the straight line obtained from plotting of $\log \mathrm{k}_{1}$ with $\log \mathrm{k}_{2}^{39}$, (Figure 5) (where $\mathrm{k}_{1}$ and $\mathrm{k}_{2}$ are the first order rate constants at different temperature) for the substitution of water in $\left[\mathrm{Cr}\left(\mathrm{H}_{2} \mathrm{O}\right)_{6}\right]^{3+}$ by valine ${ }^{26}$, glycine ${ }^{27}$, serine $^{28}$, DL- leucine ${ }^{32}, L$-glutamic acid ${ }^{30}$, DL-lysine ${ }^{32}$, aspartic acid ${ }^{29}$ and 1,3-pdta (this work).

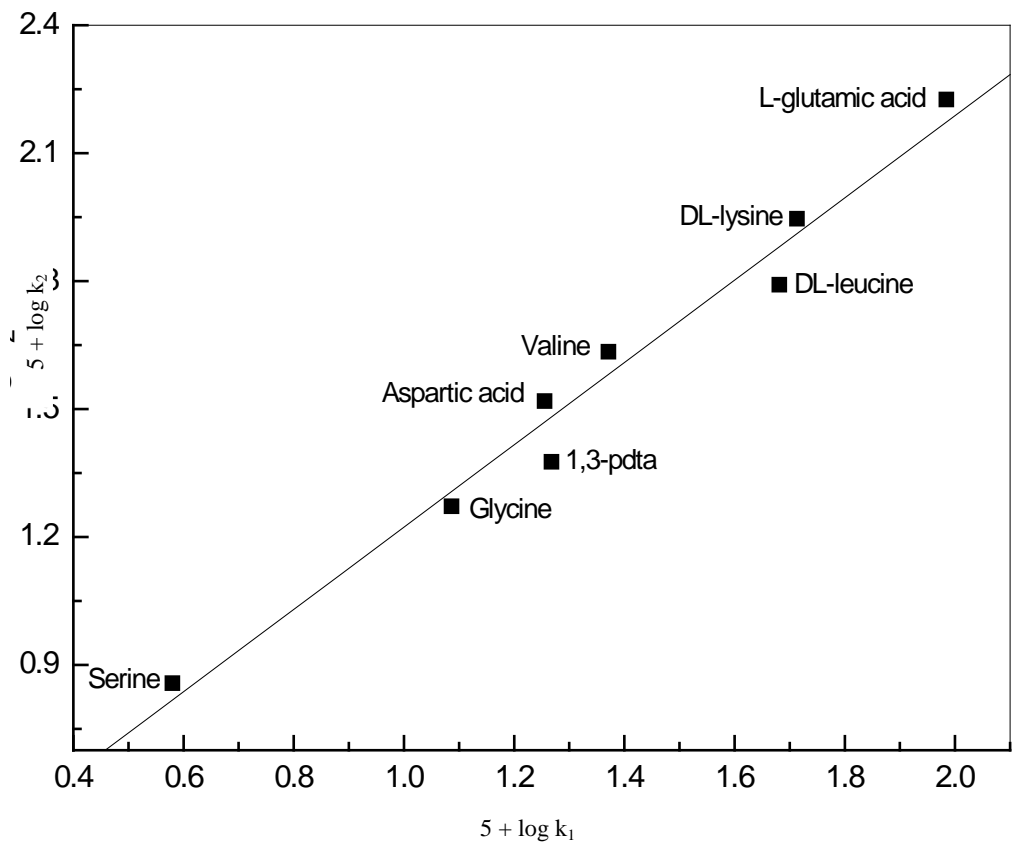

Figure 5. Plot of $\log k_{1}$ with $\log k_{2}$ for the substitution of water in $\left[\mathrm{Cr}\left(\mathrm{H}_{2} \mathrm{O}\right)_{6}\right]^{3+}$ by different ligands

The composition and formation constants of the complexes between chromium(III) and 1,3- pdta were determined using Hills equation (eq.16) ${ }^{40}$.

$$
\log \left(A-A_{0}\right) /\left(A_{\infty}-A\right)=\log K+n \log [1,3-p d t a]
$$

Where $A$ is the absorbance reached at the end of the reaction, $A_{0}$ is the absorbance at zero 1,3- pdta concentration and $\mathrm{A}_{\infty}$ is the equilibrium absorbance for highest concentration of 1,3-pdta. Plots of $\log \left(\mathrm{A}-\mathrm{A}_{0}\right) /\left(\mathrm{A}_{\infty}-\mathrm{A}\right)$ vs. $\log$ [1,3- pdta], where [1,3- pdta] is total concentration used, yield a straight line of slope $=1$ (number of ligand molecules attached to one chromium atom) and intercept of $\log \mathrm{K}=11.3$ (Figure 6). 


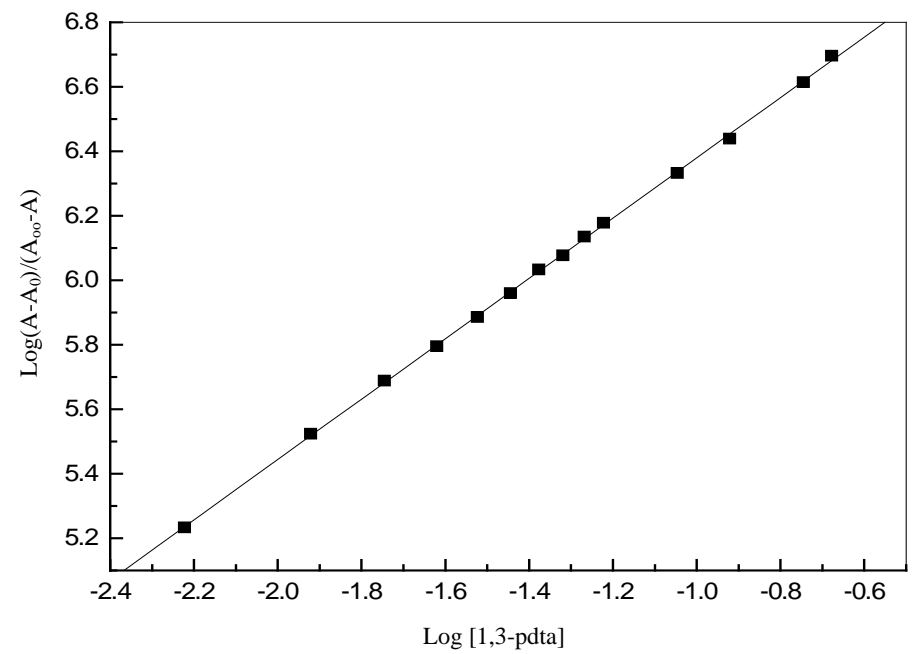

Figure 6. Plot of $\log \left(\mathrm{A}-\mathrm{A}_{0}\right) /\left(\mathrm{A}_{\infty}-\mathrm{A}\right)$ vs. $\log [1,3-\mathrm{pdta}] ; I=0.6 \mathrm{~mol} \mathrm{dm}{ }^{-3}, \mathrm{pH}=4.1$, $[\mathrm{Cr}(\mathrm{III})]=8.8 \times 10^{-3} \mathrm{~mol} \mathrm{dm}^{-3}, t=35^{0} \mathrm{C}$

\section{Conclusion}

In the present study, the kinetics of the reaction between chromium(III) and 1,3-pdta in weak acid aqueous solutions was investigated. The reaction was found to be first order in chromium(III). The reaction rate accelerated with increasing the 1,3-pdtp concentration, $\mathrm{pH}$, temperature, ionic strength and dielectric constant of the reaction medium. An associative mechanism was suggested to account for the results obtained. The logarithm of the formation constant of complex formed was found 7.31.

\section{Acknowledgement}

I am grateful to Dr. Maher I Nessim, Egyptian Petroleum Research Institute for preparation of ligand

\section{References}

1. $\quad$ Brasch N E, Buckingham D A, Clark C R and J Simpson, Inorg Chem., 1996, 35, 7728.

2. Schalfer H L and Gliemann G, Basic Principles of Ligand Field Theory; WileyInterscience: New York, 1969.

3. $\quad$ Nowack B, Environ Sci Technol., 2002, 36(19), 4009-4016.

4. Carver M A, Humphrey K M , Patchett R A and Jones C W, Eur J Biochem., 1984, 138(3), 611-615.

5. McLendon G, Hull H, Larkin K and Chang W, J Biol Inorg Chem., 1999, 4(2), 171.

6. Tandy S, Bossart K, Mueller R, Ritschel J, Hauser L, Schulin R and Nowak B, Environ Sci Technol., 2004, 38(3), 937-944.

7. Yamanishi H, Kimura S, Iyama S, Yamaguchi Y and Yanagihara T, Clin Chem., 1997, 43(12), 2413-2417.

8. Bolton H J, Li S W, Workman D J and Girvin D C, J Environ Qual., 1993, 22, 125-132.

9. $\quad$ Tolman C A, Chem Rev., 1977, 77(3), 313-348.

10. Whiltaker O, Vanderveen J E, Dinovi M J, Kusnesof P M and Dunkel V C, Reg Toxical Pharm., 1993, 18(3), 419-427. 
11. Markowitz M E, Bifur P E, Ruff H and Rosen J F, Pediatrics, 1993, 92(2), 265-271.

12. Seegers W H, Blood Clotting Enzymology; Academic Press: New York, 1967.

13. Radanovic'D J, Trifunovic' S R, Cvijovic' M S, Maricondi C and Douglas B E, Inorg Chim Acta, 1992, 196, 161-169.

14. Emorson K and Graven W M, Inorg Nucl Chem., 1959, 11, 309.

15. Swaddle T W, Adv Inorg Bioinorg Mech., 1983, 2, 95-138.

16. Swaddle T W, Rev Phy Chem Jpn, 1980, 50, 230.

17. Basolo F and Pearson R G, Mechanism of Inorganic reaction; $2^{\text {nd }}$ Edn., Wiley: New York, 1958, Ch 6.

18. Forst A A and Pearson R G, Kinetic and Mechanism; John Wiley and Sons: New York, 1961, Ch 7.

19. Shahid M, Khan I A and Kabir-ud-Din, J Chem Soc Dalton Trans., 1990, 3007.

20. Emorson K and Graven W M, J Inorg Nucl Chem., 1959, 11, 309.

21. Djudjevic'P, Radanovic'D J, Cvijovic' M S and Veselinovic' D, Talanta, 1991, 38(4), 455-460.

22. Mendola M E, Paul T, Strathmann T J and Carbonaro R F, Polyhedron, 2009, 28(2), 269-278.

23. Periumutter-Hayman B, Secco F, Tapuhi E and Venturini M, J Chem Soc Dalton Trans., 1980, 1124.

24. Campisi A and Tregloan P A, Inorg Chim Acta, 1985, 100, 251.

25. Funahshi S, Ishhihara K and Tanaka M, Inorg Chem., 1983, 22, 2070.

26. Khan I A and Kabir-ud-Din, Indian J Chem., 1984, 23A, 98.

27. Khan I A and Kabir-ud-Din, J Inorg Nucl Chem., 1981, 43, 1082.

28. Khan I A, Shahid M and Kabir-ud-Din, Indian J Chem., 1983, 23A, 382.

29. Khan I A and Kabir-ud-Din, Transition Met Chem., 1986, 11, 391.

30. Mentasti E, Secco F and Venturini M, Inorg Chem., 1982, 21(1), 602-604.

31. Guindy N M, Abou-Gamra Z M and Abdel-Messih M F, Monatshefte Fur Chemie, 2000, 131(18), 857-866.

32. Guindy N M, Abou-Gamra Z M and Abdel-Messih M F, J Chim Phys., 1999, 96(5), 851-864.

33. Espenson J H, Inorg Chem., 1969, 8, 1554.

34. Tyagi S C and Khan A A, J Inorg Nucl Chem., 1978, 40, 1899.

35. Swaddle T W, Coord Chem Rev., 1974, 14, 217.

36. Xu F C, Krouse H R and Swaddle T W, Inorg Chem., 1985, 24, 267.

37. Lincoln S F and Merbach A E, Adv Inorg Chem., 1995, 42, 1.

38. Plane R A and Taube H, J Phys Chem., 1952, 56, 33.

39. McBane G C, J Chem Educ., 1998, 75(7), 919-922.

40. Abdullah M A, Barrett J and Obrien P, J Chem Soc Dalton Trans., 1984, 1647-1650. 